\title{
Instrumento Adaptador para Facilitar Abertura de Latas
}

\section{Adaptative Tool to Facilitate the Opening of Cans}

\author{
Johanna Noordhoek ${ }^{(1)}$, Fabrícia Quintão Loschiavo ${ }^{(2)}$
}

O desvio ulnar (Figura l) é uma deformidade muito comum em adultos com artrite reumatóide (AR). Este se deve a uma interação complexa de vários fatores, incluindo a estrutura anatômica da mão, que favorece o desvio, bem como os padrões funcionais do uso e a influência dos tendões flexores durante a preensão. Na mão normal, as falanges estão em inclinação ulnar, em relação aos metacarpos. Essa inclinação se dá devido aos componentes estruturais que favorecem a direção ulnar, como, por exemplo, a forma dos ossos, o comprimento dos ligamentos colaterais e a inserção dos músculos intrínsecos. Em adição, os tendões flexores cruzam as articulações metacarpofalangeanas (MCF) no ângulo ulnar. Entretanto, o desvio ulnar não aparece na mão não-afetada pela $\mathrm{AR}$, devido aos ligamentos anulares que mantêm as articulações. Porém, quando estes ligamentos encontram-se enfraquecidos pela sinovite, eles não mais executam esta função de manutenção articular. $\mathrm{O}$ alinhamento anatômico dos tendões flexores contribui para a acentuação do desvio ulnar(1).

Todas as atividades funcionais que envolvem flexão das articulações MCF, especialmente pinça de força e preensão,

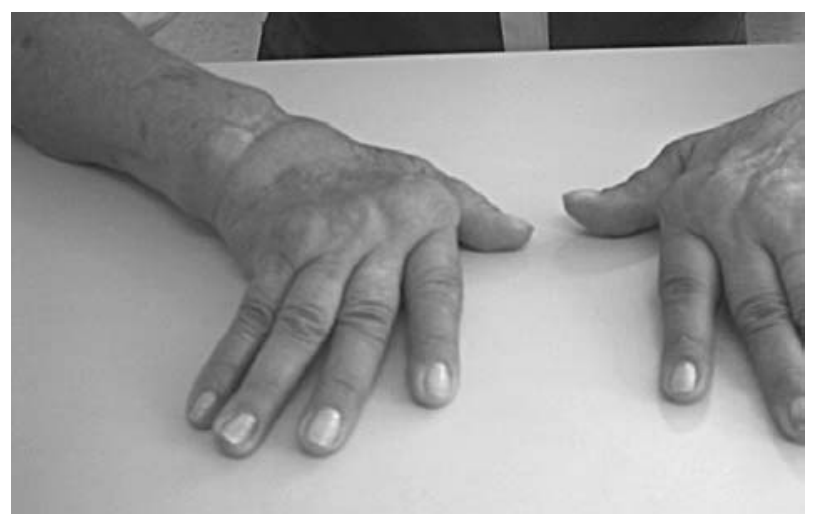

Figura 1 - Acentuado desvio ulnar. aumentam as forças desviantes nas articulações $\mathrm{MCF}^{(1)}$.

As atividades cotidianas de donas de casa, conforme o caso da paciente que recebeu a indicação para a adaptação, envolvem, em sua maioria, o desvio ulnar. Usar a faca, segurar a panela, abrir potes de conserva, abrir maçanetas esféricas, carregar objetos pesados, mexer uma panela e segurar copos são exemplos destas atividades ${ }^{(2)}$.

M., sexo feminino, 66 anos, dona de casa, atendida pelo Serviço de Terapia Ocupacional do Ambulatório Bias Fortes, do complexo Hospital das Clínicas, da Universidade Federal de Minas Gerais (UFMG), apresentou como demanda para o setor dificuldades no manuseio e abertura de latas (Figura 2).

Desta maneira, tendo em vista os objetivos da intervenção da terapia ocupacional, bem como a abordagem da tecnologia de assistência e as orientações de proteção $\operatorname{articular}^{(2,3)}$, a terapeuta ocupacional indicou a utilização da adaptação (Figuras 3 e 4), com a finalidade de proporcionar vida independente, autonomia, e melhor desempenho funcional na tarefa de abrir latas, relevante nas atividades de vida diárias (AVD’s) da paciente.

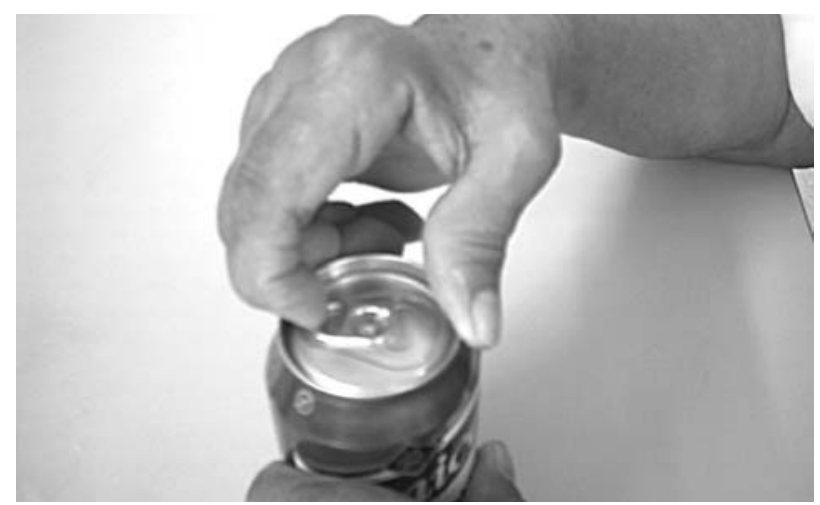

Figura 2 - Paciente abrindo a lata sem adaptação. Observa-se acentuado estresse nas pequenas articulações da mão, o que impossibilita a abertura da lata. 


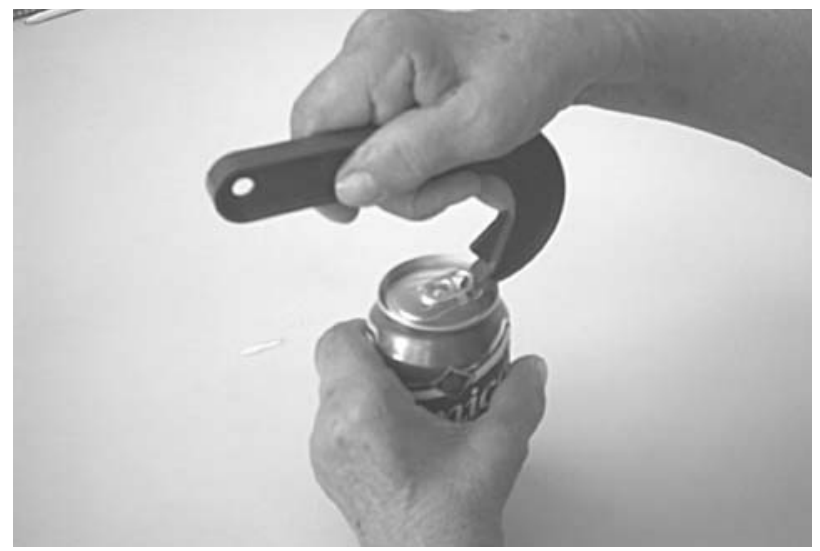

Figura 3 - Paciente abrindo a lata com o adaptador. Observa-se um melhor posicionamento das articulações, e, conseqüentemente, melhor desempenho nessa tarefa.

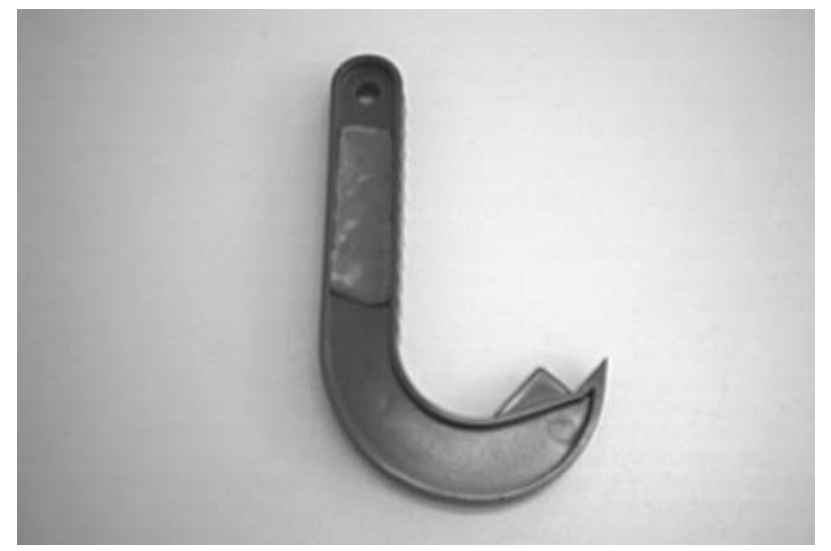

Figura 4 - Adaptador.

Declaramos a inexistência de conflitos de interesse.

\section{REFERÊNCIAS}

1. Melvin J: Rheumatic Diseases: Occupational Therapy and Rehabilotation. 2 ed. Philadelphia. FA Davis Company, 1982.

2. Noordhoek J, Loschiavo FQ: Intervenção da Terapia Ocupacional no Tratamento de Indivíduos com Doenças
Reumáticas Utilizando a Abordagem da Proteção Articular. Rev Bras Reumatol 45: 242-4, 2005.

3. Noordhoek J, Loschiavo FQ: Adaptação Visando Melhora do Desempenho Funcional em Atividade de Vida Diária para Adolescente com Artrite Reumatóide Juvenil. Rev Bras Reumatol 44: 362-3, 2004.

Rev Bras Reumatol, v. 46, n.5, p. 347-348, set/out, 2006 